\title{
BMJ Open Knowledge of blood donation and associated factors in Ethiopia: a systematic review and meta-analysis
}

\author{
Addisu Getie (1) , ${ }^{1}$ Adam Wondmieneh (D) , ${ }^{1}$ Melaku Bimerew, ${ }^{1}$ \\ Getnet Gedefaw (D) ,2 Asmamaw Demis (D) ${ }^{1}$
}

To cite: Getie A, Wondmieneh A, Bimerew M, et al. Knowledge of blood donation and associated factors in Ethiopia: a systematic review and meta-analysis. BMJ Open 2021;11:e044343. doi:10.1136/ bmjopen-2020-044343

- Prepublication history and additional supplemental material for this paper are available online. To view these files, please visit the journal online (http://dx.doi.org/10.1136/ bmjopen-2020-044343).

Received 31 August 2020 Accepted 15 June 2021

Check for updates

(c) Author(s) (or their employer(s)) 2021. Re-use permitted under CC BY-NC. No commercial re-use. See rights and permissions. Published by BMJ.

${ }^{1}$ Nursing, Woldia University, Woldia, Ethiopia

${ }^{2}$ Midwifery, Woldia University, Woldia, Ethiopia

Correspondence to

Addisu Getie;

addisugetie@gmail.com

\section{ABSTRACT}

Objective To assess the level of knowledge about blood donation and associated factors in Ethiopia.

Design Systematic review and meta-analysis.

Methods Both published and unpublished cross-

sectional studies on the level of knowledge about blood donation in Ethiopia were included. Articles from different databases such as PubMed/MEDLINE, HINARI, EMBASE, Scopus, Google Scholar and African Journals Online were searched. Cochrane $\mathrm{I}^{2}$ statistics were used to check for heterogeneity. Subgroup and sensitivity analyses of evidence of heterogeneity were carried out. Egger's test with funnel plot was conducted to investigate publication bias.

Result Twenty cross-sectional studies with a total of 8338 study participants (4712 men and 3626 women) were included. The overall nationwide level of knowledge about blood donation was $56.57 \%$ (95\% Cl 50.30 to 62.84$)$. Being in secondary school and above (adjusted $\mathrm{OR}=3.12$; $95 \% \mathrm{Cl} 2.34$ to 4.16 ) and being male (adjusted $\mathrm{OR}=1.81$; $95 \% \mathrm{Cl} 1.44$ to 2.28 ) were the factors associated with level of knowledge about blood donation.

Conclusion More than half of the study participants were knowledgeable about blood donation. Sex and educational status were the factors significantly associated with level of knowledge about blood donation in Ethiopia. Therefore, there is a need for education and dissemination of information about blood donation among the general population to build adequate knowledge and maintain regular blood supply.

\section{INTRODUCTION}

Blood donation is life-saving for people in different emergency conditions, such as road traffic accidents, surgical procedures, pregnancy and delivery complications, chemotherapy, and diseases such as malaria, anaemia and intestinal parasites. ${ }^{1}$ Blood donation is a noble practice of saving the life of millions of people. Donating safe and adequet blood can safe up to three lives of a patient who need blood. $^{2}$

Although the demand for adequate and safe blood is significantly increasing, there is a serious and critical shortage of blood stocks in low-income and middle-income countries.

\section{Strengths and limitations of this study}

This study highlights the nationwide level of knowledge about blood donation in Ethiopia.

- This study covers a wide area and investigates different articles, making the review more accurate.

- Subgroup and sensitivity analyses were carried out to investigate the heterogeneity of the included studies.

- All included studies were cross-sectional in design, which may limit investigation of the cause-effect relationship.

In low-income and middle-income countries, family replacement and paid blood donors are the most common sources of blood transfusion. ${ }^{3}$ The availability of blood for transfusion in low-income countries is very limited due to the low level of knowledge, unwillingness to donate blood and poor blood donation practices. Meanwhile, patients suffer from lack of blood transfusion due to increased need from different medical and surgical conditions ${ }^{4}$

While every blood donor is considered a hero, the amount of blood collected from donors and the average rate of blood collection in low-income countries including Ethiopia are low compared with the demand for blood. ${ }^{5}$ The act of family replacement therapy is a common blood donation practice than collecting from volunteer blood donors, which is a common predisposing factor for misconception towards blood donation practice. ${ }^{6}$

As different studies have shown, the prevalence of level of knowledge regarding blood donation ranged from $32.4 \%$ to $40.45 \% .^{7} 48$ Education, sensitisation of blood donation, increasing public awareness, and campaign through the internet and media are recommended strategies to increase awareness, attitude and motivational practice of blood donation. ${ }^{9-11}$ Fear of the different health risks after blood donation and lack of information 
on where, when and how to donate blood are the most common factors that hinder blood donation. ${ }^{12}$ Even though beliefs, attitudes and behaviours regarding blood donation differ, adequate knowledge is needed among non-donors. There is a gap between willingness to donate blood and the number of donors in most populations around the world, which affects the practice of blood donation. ${ }^{13}$ There is a need to spread awareness on blood donation among the general population to maintain an adequate and safe blood supply, which can be done through well-designed communication strategies to overcome the problem. ${ }^{7}$

While there is a very high need for blood supply in Ethiopia, there is a serious shortage of blood stocks in the country. Thus, identifying the different factors that hinder knowledge about the practice of blood donation is essential. This systematic review and meta-analysis aims to review the different studies conducted so far on the level of knowledge about blood donation and associated factors in Ethiopia.

\section{METHODS AND MATERIALS \\ Study protocol}

In this meta-analysis, the Preferred Reporting Items for Systematic Review and Meta-analysis guidelines for reporting of findings were used ${ }^{14}$ (online supplemental table S1).

\section{Databases and search strategy}

Different databases such as PubMed/MEDLINE, Hinari, EMBASE, Google Scholar and African Journals Online were used to search for available articles. Both published and unpublished articles from the repository of Ethiopian universities were also searched. The search date was from 1 January 2000 up to 1 May 2021. Articles reporting on knowledge about blood donation and associated factors in Ethiopia were included in the final analysis. The search items were "knowledge" OR "awareness" AND "blood donation" OR "volunteer blood donation" AND "associated factors" OR "determinant factors" AND "Ethiopia". These search strings were developed using "AND" and "OR" Boolean operators (table 1).

\section{Search and eligibility of studies}

All retrieved articles were exported to EndNote reference software V.8 citation manager (Thomson, Stamford, Connecticut, USA) to sort and delete duplicates. Two investigators (AG and $\mathrm{AD}$ ) independently evaluated each article by title and abstract, assessed the eligibility of the articles, and critically reviewed the selected articles. Extraction was done by author name, publication year, region where the study was conducted, study subjects, sampling method, method of survey, study period, sample size, study design, level of education, level of knowledge regarding blood donation and factors associated with level of knowledge about blood donation.

\section{Eligibility criteria}

Both published and unpublished cross-sectional studies conducted on the level of knowledge about blood donation among populations in Ethiopia were included, whereas qualitative studies, different trials, case reports, review articles, updates and news were excluded from the analysis. Furthermore, articles not reporting on the outcome of the study and those without full texts were excluded.

\section{Outcome measurement of the study}

There are two main outcomes, namely level of knowledge about blood donation and the factors associated with it. Level of knowledge was measured using the mean score on the knowledge assessment questions. Study participants who scored with a mean score and above on the knowledge assessment items were considered knowledgeable about blood donation, whereas those who scored below the mean score were considered not knowledgeable.

\section{Quality assessment}

Two authors (AG and $\mathrm{AD}$ ) independently assessed the quality of the studies using the Newcastle-Ottawa Scale for cross-sectional studies. ${ }^{15}$ Methodological quality, comparability, outcome and statistical analysis of the studies were the main assessment tools used to determine quality. Studies that scored $\geq 7$ out of 10 were considered to be of high quality. During quality appraisal of the articles, any discrepancies between the two authors were resolved. All

Table 1 Search of different databases for studies about level of knowledge and associated factors regarding blood donation in Ethiopia

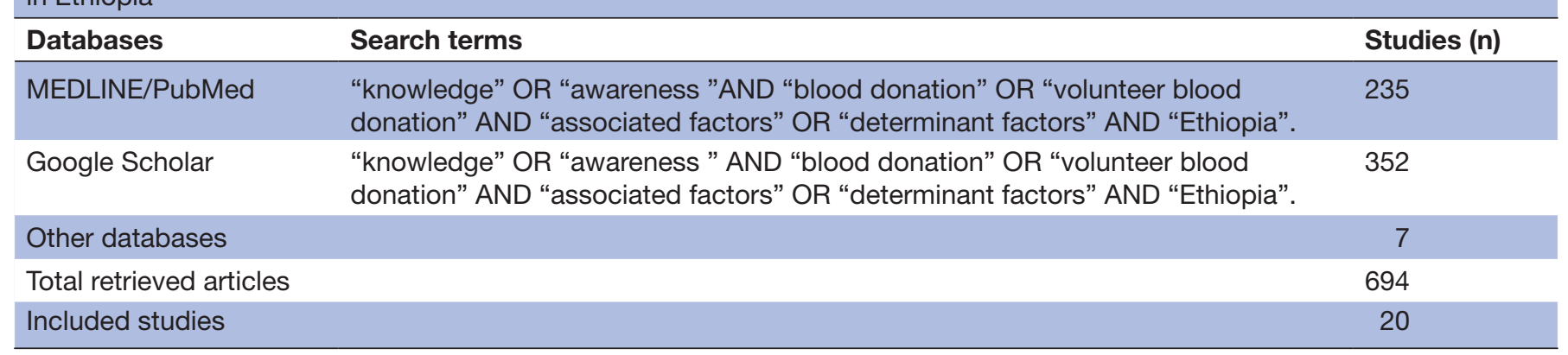


authors independently assessed the eligibility of the articles to be considered in the final analysis.

\section{Data processing and analysis}

In this systematic review and meta-analysis, a weighted inverse variance random-effects model at $95 \%$ CI was used to calculate the pooled prevalence of level of knowledge about blood donation and the associated factors. ${ }^{16}$ After extraction and cleaning using Microsoft Excel spreadsheets, the data were exported to STATA V.11 statistical software for analysis. The heterogeneity of the studies was assessed using the Cochrane Q-test and $\mathrm{I}^{2}$ with the corresponding $\mathrm{p}$ value. $\mathrm{I}^{2}$ values of $25 \%, 50 \%$ and $75 \%$ represent low, moderate and high heterogeneity, respectively. ${ }^{17}$ The source of heterogeneity was examined through subgroup analysis based on region, study subjects, study setting and sample size. Sensitivity analysis was also carried out to confirm the presence or absence of influential studies. The presence of publication bias was evaluated using Egger's test and presented with funnel plots. ${ }^{18}$ For associated factors, log OR was used to decide on the association between the associated factors and the level of knowledge about blood donation. A statistical test with a $p$ value of less than 0.05 was considered statistically significant. ${ }^{19}$

\section{Patient and public involvement}

It was not appropriate or possible to involve the patients or the public in the design, conduct, reporting or dissemination plans of our research.

\section{RESULTS}

Six hundred and ninety-four articles were retrieved. Of these retrieved articles, 284 were excluded due to duplication. Three hundred and sixty-eight articles were further excluded after reviewing the titles and abstracts. Furthermore, 22 articles which did not fulfil the inclusion criteria were excluded. Finally, 20 articles were used in the analysis (figure 1).

\section{Characteristics of the studies and study participants}

Twenty cross-sectional studies with a total of 8338 study participants (4712 men and 3626 women) were involved. Of the included articles, eight were from the Amhara region, ${ }^{1}{ }^{12}{ }^{20-25}$ five from the Oromia region, ${ }^{46-29}$ two from the Addis Ababa city administration, ${ }^{50}$ two from Southern Nations, Nationalities and Peoples Region, ${ }^{31} 32$ two from Tigri region, ${ }^{33} 34$ and the remaining was from the Afar region. ${ }^{35}$ The sample size of the included studies ranged from 218 to 845 (table 2).

\section{Knowledge about blood donation}

The overall pooled prevalence of level of knowledge about blood donation in Ethiopia was 56.57\% (95\% CI 50.30 to 62.84 ) (figure 2 ).

\section{Heterogeneity and publication bias}

In this systematic review and meta-analysis, heterogeneity was identified within the studies $\left(\mathrm{I}^{2}=97.3 \%, \mathrm{p}<0.001\right)$. The funnel plot showed an asymmetrical distribution of studies included in the review and a statistically significant

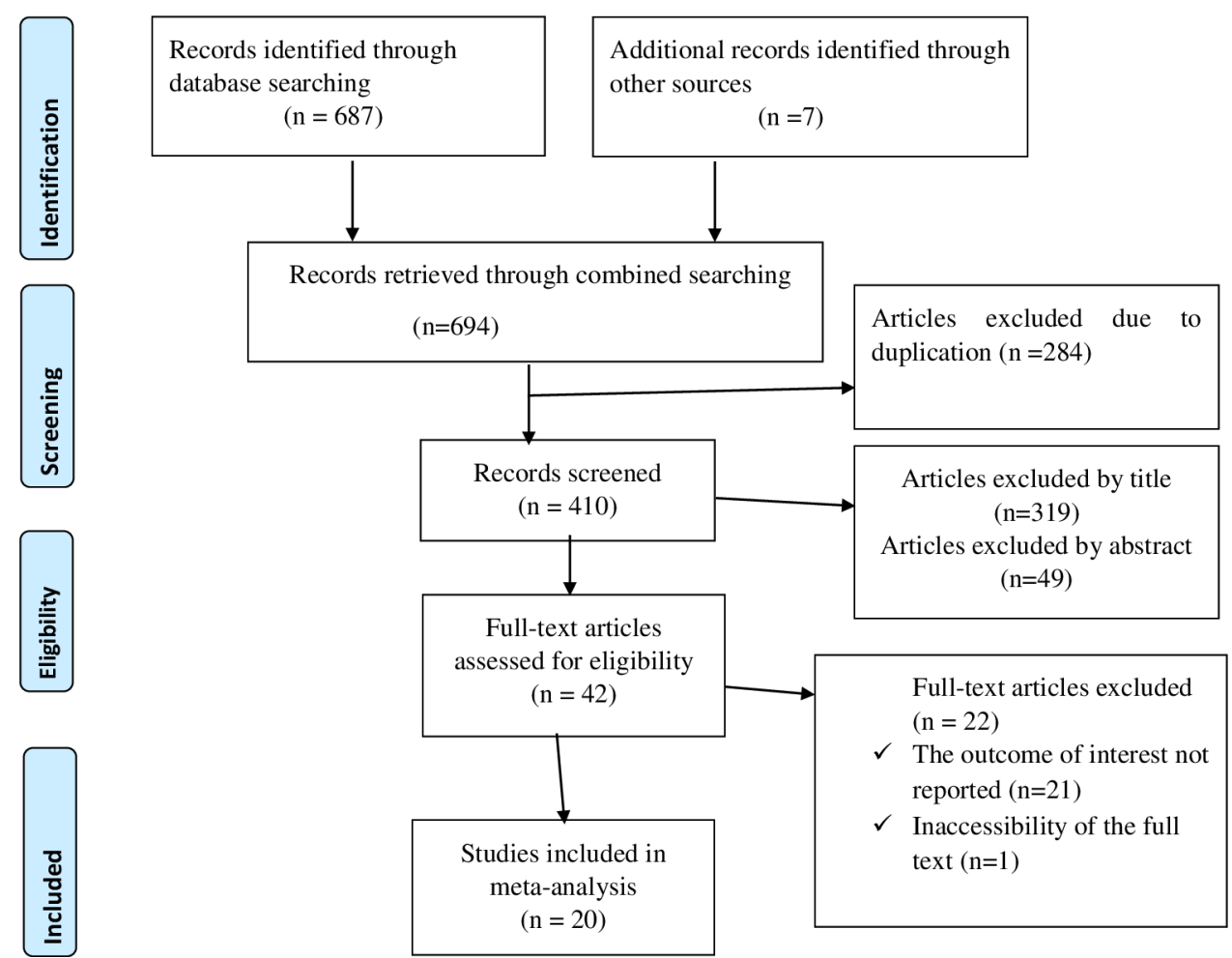

Figure 1 Flow chart of selection of studies for the systematic review and meta-analysis of the level of knowledge about blood donation and associated factors in Ethiopia. 
Table 2 Characteristics of studies included in the review and meta-analysis of knowledge about blood donation and associated factors in Ethiopia

\begin{tabular}{|c|c|c|c|c|c|c|}
\hline Author & $\begin{array}{l}\text { Publication } \\
\text { year }\end{array}$ & Region & Study participants & Method of survey & Sample size & Prevalence \\
\hline Misganaw et $\left.a\right|^{5}$ & 2014 & Addis Ababa & University student & Self-administered & 384 & 83.59 \\
\hline Teklu et $a l^{30}$ & 2015 & Addis Ababa & Healthcare worker & Self-administered & 295 & 54.24 \\
\hline $\begin{array}{l}\text { Nigatu and } \\
\text { Demissie }^{4}\end{array}$ & 2014 & Oromia & University student & Self-administered & 399 & 40.35 \\
\hline Mulatu et $a l^{32}$ & 2017 & SNNPR & Community & Face-to-face interview & 250 & 76.00 \\
\hline Abera et al ${ }^{1}$ & 2017 & Amhara & Healthcare worker & Self-administered & 276 & 75.36 \\
\hline $\begin{array}{l}\text { Mekonnen and } \\
\text { Melesse }^{23}\end{array}$ & 2016 & Amhara & Community & Face-to-face interview & 387 & 56.07 \\
\hline Addisu et $a^{20}$ & 2017 & Amhara & Community & Face-to-face interview & 376 & 38.30 \\
\hline Malako et $a l^{31}$ & 2019 & SNNPR & Healthcare worker & Self-administered & 218 & 82.57 \\
\hline Enawgaw et $a l^{25}$ & 2019 & Amhara & Community & Face-to-face interview & 401 & 35.41 \\
\hline Melku et al ${ }^{12}$ & 2016 & Amhara & Community & Face-to-face interview & 768 & 56.77 \\
\hline Melku et $a l^{24}$ & 2018 & Amhara & University student & Self-administered & 255 & 48.24 \\
\hline Arage et $a l^{21}$ & 2017 & Amhara & Healthcare worker & Self-administered & 427 & 51.99 \\
\hline Urgesa et $a l^{29}$ & 2017 & Oromia & Community & Face-to-face interview & 845 & 43.55 \\
\hline Tadesse et $a l^{34}$ & 2018 & Tigri & Healthcare worker & Self-administered & 556 & 57.19 \\
\hline Tadesse et $\left.a\right|^{35}$ & 2017 & Afar & University student & Self-administered & 339 & 53.98 \\
\hline Seid et $a l^{33}$ & 2017 & Tigri & Healthcare worker & Self-administered & 237 & 70.46 \\
\hline
\end{tabular}

SNNPR, South Nations, Nationalities and Peoples Region.

Egger's test $(\mathrm{p}=0.02)$, suggesting the presence of publication bias (figure 3 ).

\section{Subgroup analysis}

Subgroup analysis was done by region, study subjects, study setting and sample size. The highest pooled prevalence of level of knowledge about blood donation was reported by healthcare workers $(65.28 \%, 95 \%$ CI 55.16 to 75.40). Similarly, the level of knowledge about blood donation was higher among studies done in institutions (institution-based) $(60.45 \%, 95 \%$ CI 51.05 to 69.83$)$ than studies conducted in the community (table 3 ).

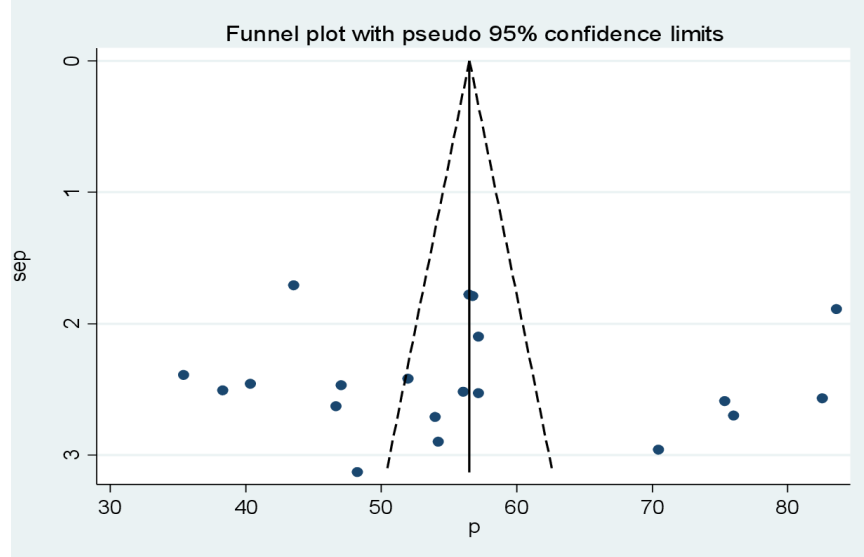

Figure 3 Funnel plot with 95\% confidence limits of the pooled prevalence of knowledge about blood donation and associated factors in Ethiopia. sep; standared error of prevalence.
Figure 2 Forest plot of the pooled prevalence of knowledge about blood donation and associated factors in Ethiopia. ES, Effect Size. 
Table 3 Subgroup analysis of the level of knowledge about blood donation and associated factors in Ethiopia ( $\mathrm{n}=20$ )

\begin{tabular}{|c|c|c|c|c|c|c|}
\hline Variables & Subgroup & Studies (n) & Population & Prevalence $(95 \% \mathrm{Cl})$ & $I^{2}(\%)$ & $P$ value \\
\hline \multirow[t]{2}{*}{ Region } & Northern Ethiopia & 10 & 4455 & 54.81 (47.65 to 61.57$)$ & 95.7 & $<0.001$ \\
\hline & Southern Ethiopia & 5 & 1637 & 58.52 (41.66 to 76.38$)$ & 98.2 & $<0.001$ \\
\hline \multirow[t]{2}{*}{ Study participants } & Healthcare workers & 6 & 2009 & 65.28 (55.16 to 75.40$)$ & 95.9 & $<0.001$ \\
\hline & Community & 9 & 4592 & 51.84 (44.60 to 59.08$)$ & 96.1 & $<0.001$ \\
\hline \multirow[t]{2}{*}{ Study setting } & Institution-based & 11 & 3746 & 60.45 (51.05 to 69.83$)$ & 97.5 & $<0.001$ \\
\hline & Community-based & 9 & 4592 & 51.84 (44.80 to 59.08$)$ & 96.1 & $<0.001$ \\
\hline \multirow[t]{2}{*}{ Sample size } & $<400$ & 13 & 4159 & 60.25 (51.20 to 6931$)$ & 97.6 & $<0.001$ \\
\hline & $\geq 400$ & 7 & 4179 & 49.84 (43.90 to 55.79$)$ & 93.5 & $<0.001$ \\
\hline
\end{tabular}

Other: Addis Ababa, Eastern Ethiopia.

\section{Sensitivity analysis}

As shown in table 4, all of the point's estimates are within the overall $95 \%$ CI, which confirms that omission of any of the studies included in this systematic review and metaanalysis does not affect the overall prevalence of the level of knowledge about blood donation.

\section{Factors associated with knowledge about blood donation}

In this study, participants' sex and level of education were significant factors associated with level of knowledge about

Table 4 Sensitivity analysis of knowledge about blood donation and associated factors in Ethiopia

\begin{tabular}{|c|c|c|}
\hline Study omitted & $\begin{array}{l}\text { Estimated } \\
\text { prevalence }\end{array}$ & $95 \% \mathrm{Cl}$ \\
\hline Misganaw et $\left.a\right|^{5}$ & 55.12 & 49.57 to 60.67 \\
\hline Teklu et al (2015) $)^{30}$ & 56.69 & 50.15 to 63.24 \\
\hline Nigatu and Demissie ${ }^{4}$ & 57.42 & 51.04 to 63.80 \\
\hline Mulatu et $a l^{32}$ & 55.55 & 49.24 to 6186 \\
\hline Gebresilase et $\left.a\right|^{26}$ & 57.09 & 50.58 to 63.59 \\
\hline Abera et al ${ }^{1}$ & 55.58 & 49.27 to 61.90 \\
\hline Mekonnen and Melesse ${ }^{23}$ & 56.60 & 50.01 to 63.18 \\
\hline Addisu et $\mathrm{al}^{20}$ & 57.53 & 51.20 to 63.86 \\
\hline Malako et $\left.\mathrm{a}\right|^{31}$ & 55.21 & 49.14 to 61.27 \\
\hline Beyene $^{27}$ & 57.07 & 50.55 to 63.59 \\
\hline Mijena et $a l^{28}$ & 56.54 & 49.95 to 63.12 \\
\hline Jemberu et $a l^{22}$ & 56.57 & 49.84 to 63.31 \\
\hline Enawgaw et $a^{25}$ & 57.69 & 51.48 to 63.90 \\
\hline Melku et $a l^{12}$ & 56.56 & 49.83 to 63.29 \\
\hline Melku et $a^{24}$ & 57.00 & 50.50 to 63.50 \\
\hline Arage et $a l^{21}$ & 56.81 & 50.23 to 63.39 \\
\hline Urgesa et $a l^{29}$ & 57.27 & 50.82 to 63.72 \\
\hline Tadesse et $a l^{34}$ & 56.54 & 49.89 to 63.19 \\
\hline Tadesse et $a l^{35}$ & 56.71 & 50.14 to 62.28 \\
\hline Seid et $\left.a\right|^{33}$ & 55.85 & 49.41 to 62.28 \\
\hline Overall & 56.57 & 50.30 to 62.84 \\
\hline
\end{tabular}

blood donation. The odds of level of knowledge were 1.81 times more likely among men than women (adjusted OR $(\mathrm{AOR})=1.81 ; 95 \%$ CI 1.44 to 2.28 ) (figure 4 ). Similarly, the odds of level of knowledge were 3.12 times more likely among participants whose educational status was above secondary school than those who did not attend any formal education ( $\mathrm{AOR}=3.12 ; 95 \% \mathrm{CI} 2.34$ to 4.16 ) (figure 5).

\section{DISCUSSION}

In this systematic review and meta-analysis, the pooled prevalence of good knowledge about blood donation is $56.57 \%$ (95\% CI 50.30 to 62.84 ), which indicates that there is a lack of adequate knowledge about blood donation in the country. This might be due to the absence of regular blood donation programmes, less media coverage, limited campaign and limited educational access with regard to blood donation in the country.

The level of knowledge in this study is lower than the studies conducted in Malaysia $(98 \%),{ }^{2}$ Barabanki, India $(90 \%),{ }^{36}$ and Benin City, Nigeria $(92.65 \%) .{ }^{37}$ This variation might be due to differences in study participants. In

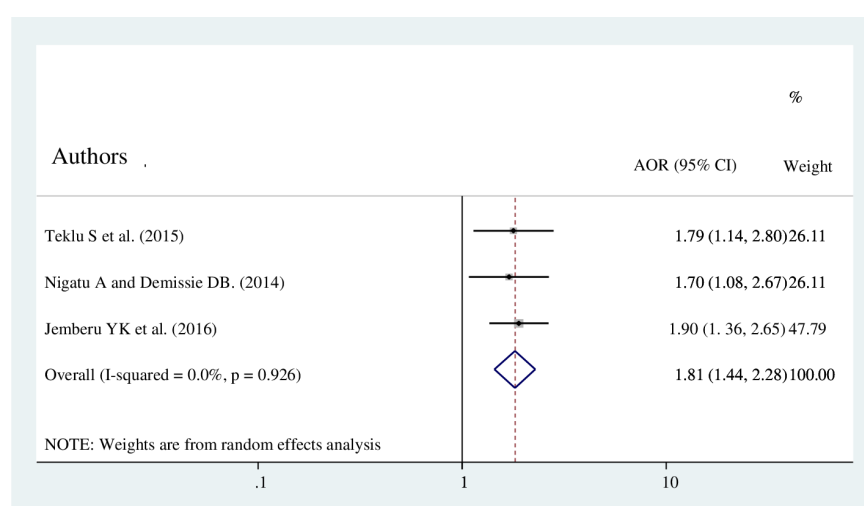

Figure 4 Overall pooled OR of the association between sex and level of knowledge about blood donation in Ethiopia. AOR, adjusted OR. 


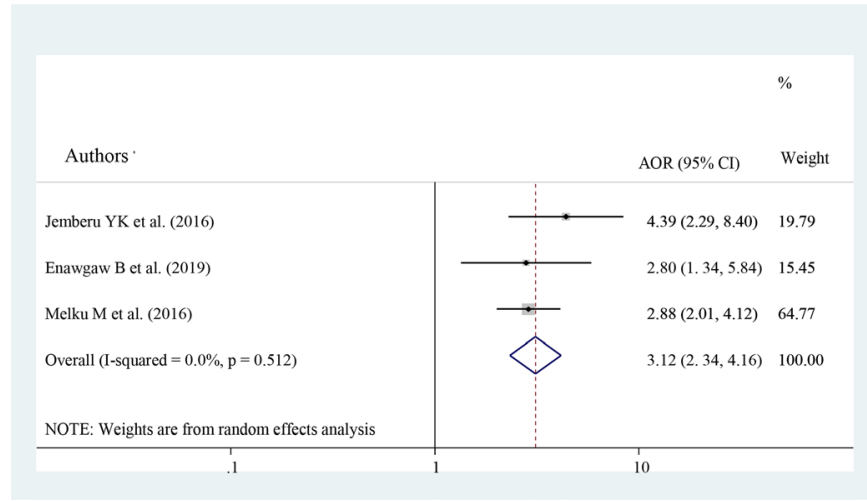

Figure 5 Overall pooled OR of the association between educational status and level of knowledge about blood donation in Ethiopia. AOR, adjusted OR.

Malaysia, the study participants were nursing students; in Benin City, Nigeria the study participants were healthcare workers; and in Barabanki, India the study participants were undergraduate medical students. In contrast, this study targeted all populations in the country. This variation might also be due to the status and level of media coverage and the educational status of people in Ethiopia; Ethiopia is one of the low-income countries with very limited education coverage and media accessibility. There is an almost similar finding with regard to knowledge about blood donation with a study done among students of a tertiary institution in Nigeria. ${ }^{9}$ However, the finding of this study is higher than the studies conducted in Kerala, India $(35 \%)^{7}$ and in Nepal $(32 \%),{ }^{8}$ which may be due to time variations, where the previous studies were conducted before 7 and 5 years, respectively.

In the subgroup analysis, there was no significant variation with regard to the prevalence of knowledge about blood donation within the region where the studies were done. However, there were variations with regard to knowledge prevalence within study participants, study setting and sample size categories. Accordingly, the highest prevalence of knowledge was reported among healthcare workers. This is because healthcare workers have formal education on blood donation and know more about human physiology than others. Healthcare workers may also have experience with blood donation. This agreed with a study conducted in developing countries where regular donors had good knowledge compared with nondonors. ${ }^{13}$ Studies conducted in institutions (institutionbased) showed a higher prevalence of knowledge than studies conducted in the community (community-based). This is due to the populations in institutions having more access to information. ${ }^{7}$

In this systematic review and meta-analysis, the odds of knowledge about blood donation were 1.81 times more likely among men than women. This might be due to women being more prone to different physiological conditions such as menstruation and bleeding during pregnancy and delivery, which deter them from donating blood. As a result they have poor blood donation practices when compared with men. This poor practice may indirectly affect women's knowledge about blood donation. ${ }^{3}$ Educational status also had a significant association with knowledge about blood donation. The odds of knowledge about blood donation were 3.12 times more likely among participants who had a level of education above secondary school compared with illiterates. ${ }^{11}$ This is because formal education is the cornerstone of acquiring knowledge. Therefore, participants who reached secondary school and above have more access to information than participants who did not have any formal education.

\section{Limitations of the study}

All studies included in this systematic review and metaanalysis were cross-sectional studies, which may limit the generation of a cause-effect link between independent and dependent variables.

\section{CONCLUSION}

More than half of the study participants were knowledgeable about blood donation. Sex and educational status were significantly associated with level of knowledge about blood donation in Ethiopia. Therefore, there is a need for education and dissemination of information about blood donation among the general population to build adequate knowledge and maintain regular blood supply.

Contributors $A G$ and $M B$ designed the study, as well as designed and run the literature search. AG, AW, MB, GG and AD acquired the data, screened the records, extracted the data and assessed the risk of bias. $A G$ and $A D$ did the statistical analyses and wrote the report. All authors provided critical conceptual input, analysed and interpreted the data, and critically revised the report. All authors read and approved the final manuscript.

Funding The authors have not declared a specific grant for this research from any funding agency in the public, commercial or not-for-profit sectors.

Competing interests None declared.

Patient consent for publication Not required.

Provenance and peer review Not commissioned; externally peer reviewed.

Data availability statement All data relevant to the study are included in the article or uploaded as supplementary information.

Supplemental material This content has been supplied by the author(s). It has not been vetted by BMJ Publishing Group Limited (BMJ) and may not have been peer-reviewed. Any opinions or recommendations discussed are solely those of the author(s) and are not endorsed by BMJ. BMJ disclaims all liability and responsibility arising from any reliance placed on the content. Where the content includes any translated material, BMJ does not warrant the accuracy and reliability of the translations (including but not limited to local regulations, clinical guidelines, terminology, drug names and drug dosages), and is not responsible for any error and/or omissions arising from translation and adaptation or otherwise.

Open access This is an open access article distributed in accordance with the Creative Commons Attribution Non Commercial (CC BY-NC 4.0) license, which permits others to distribute, remix, adapt, build upon this work non-commercially, and license their derivative works on different terms, provided the original work is properly cited, appropriate credit is given, any changes made indicated, and the use is non-commercial. See: http://creativecommons.org/licenses/by-nc/4.0/.

ORCID iDs

Addisu Getie http://orcid.org/0000-0002-0572-3414

Adam Wondmieneh http://orcid.org/0000-0002-3986-8072

Getnet Gedefaw http://orcid.org/0000-0003-4906-2555

Asmamaw Demis http://orcid.org/0000-0003-4127-8642 


\section{REFERENCES}

1 Abera B, Mohammed B, Betela W, et al. Knowledge, attitude, and practice towards blood donation among health care providers in hospitals at Bahir Dar City, Ethiopia. Transfus Apher Sci 2017;56:434-8.

2 Ariffin SM, Rafi N, Aung KT. Knowledge, attitude, and practice of nursing and computer science students on blood donation. A comparison study. Age 2017;21:21-3.

3 Benedict N, Usimenahon A, Alexander NI, et al. Knowledge, attitude and practice of voluntary blood donation among physicians in a tertiary health facility of a developing country. International Journal of Blood transfusion and Immunohematology 2012;2:4.

4 Nigatu A, Demissie DB. Knowledge, attitude and practice on voluntary blood donation and associated factors among Ambo university regular students, Ambo town, Ethiopia. J Community Med Health Educ 2014;4:6.

5 Misganaw C, Tenkir M, Deresa A. The level and associated factors of knowledge, attitude, and practice of blood donation among health science students of Addis Ababa university. IJMHSR 2014;1:105-18.

6 Alam M, Masalmeh BED, Knowledge EDMB. Knowledge, attitudes and practices regarding blood donation among the Saudi population. Saudi Med J 2004;25:318-21.

7 Aslami AN, Jobby A, Simon S, et al. Assessment of knowledge, attitude and practice (KAP) of blood donation among MBBS students of a medical college in Kollam, Kerala. J Evol Med Dent Sci 2015;4:6086-95.

8 Amatya M. Study on knowledge, attitude, and practice of blood donation among students of different colleges of Kathmandu, Nepal. International Journal of Pharmaceutical and Biological Archives 2013;4:424-8.

9 Salaudeen AG, Odeh E. Knowledge and behavior towards voluntary blood donation among students of a tertiary institution in Nigeria. Niger J Clin Pract 2011;14:303-7.

10 Waheed U, Azmat M, Knowledge ZH. Knowledge, attitude and practices towards blood donation in Pakistan: a nationwide survey. HTIJ 2015;1:00018.

11 Rathod GB, Parmar P. Comparison regarding knowledge, attitude, and practice of blood donation between health professionals and the general population. International Journal of Current Research and Review 2012;4:114.

12 Melku M, Terefe B, Asrie F, et al. Knowledge, attitude, and practice of adult population towards blood donation in Gondar town, Northwest Ethiopia: a community based cross-sectional study. J Blood Transfus 2016;2016:1-10.

13 Lownik E, Riley E, Konstenius T, et al. Knowledge, attitudes and practices surveys of blood donation in developing countries. Vox Sang 2012;103:64-74.

14 Moher D, Liberati A, Tetzlaff J, et al. Preferred reporting items for systematic reviews and meta-analyses: the PRISMA statement. PLoS Med 2009;6:e1000097.

15 Peterson J, Welch V, Losos M. The Newcastle-Ottawa scale (NOS) for assessing the quality of nonrandomized studies in meta-analyses. Ottawa: Ottawa Hospital Research Institute, 2011.

16 Borenstein M, Hedges LV, Higgins JPT, et al. A basic introduction to fixed-effect and random-effects models for meta-analysis. Res Synth Methods 2010;1:97-111.

17 Rücker G, Schwarzer G, Carpenter JR, et al. Undue reliance on I ${ }^{(2)}$ in assessing heterogeneity may mislead. BMC Med Res Methodol 2008;8:79.

18 Egger M, Davey Smith G, Schneider M, et al. Bias in meta-analysis detected by a simple, graphical test. BMJ 1997;315:629-34.

19 Getie A, Wondmieneh A, Bimerew M, et al. Blood donation practice and associated factors in Ethiopia: a systematic review and metaanalysis. Biomed Res Int 2020;2020:1-8.
20 Addisu A, Sultan H, Deginet T. Assessment of knowledge, attitude, and practice of voluntary blood donation and associated factors among residents of Birbir town. J Community Med Health Educ 2017;7:2161-711.

21 Arage G, Ibrahim S, Adimasu E. Blood donation practice and its associated factors among health professionals of University of Gondar Hospital, Northwest Ethiopia: a cross sectional study. BMC Res Notes 2017;10:1-6

22 Jemberu YA, Esmael A, Ahmed KY. Knowledge, attitude and practice towards blood donation and associated factors among adults in Debre Markos town, Northwest Ethiopia. BMC Hematol 2016;16:23.

23 Mekonnen FH, Melesse ST. Status and deterrents of blood donation among civil servants in Bahir Dar, Ethiopia. Ethiopian Journal of Health Development 2016;30:44-9.

24 Melku M, Asrie F, Shiferaw E. Knowledge, attitude and practice regarding blood donation among graduating undergraduate health science students at the University of Gondar, Northwest Ethiopia. Ethiopian Journal of health sciences 2018;28.

25 Enawgaw B, Yalew A, Shiferaw E. Blood donors' knowledge and attitude towards blood donation at North Gondar district blood bank, Northwest Ethiopia: a cross-sectional study. BMC Res Notes 2019;12:729.

26 Gebresilase HW, Fite RO, Abeya SG. Knowledge, attitude and practice of students towards blood donation in Arsi university and Adama science and technology university: a comparative cross sectional study. BMC Hematol 2017;17:20.

27 Beyene GA. Voluntary blood donation knowledge, attitudes, and practices in central Ethiopia. Int J Gen Med 2020;13:67-76.

28 Mijena GF, Nigussie S, Gobena T. Voluntary blood donation practice and associated factors among civil servants in Chiro town of Western Hararghe zone. Eastern Ethiopia: a cross-sectional study 2019.

29 Urgesa K, Hassen N, Seyoum A. Knowledge, attitude, and practice regarding voluntary blood donation among adult residents of Harar town, eastern Ethiopia: a community-based study. J Blood Med 2017;8:13-20.

30 Knowledge TS. Attitude, practice, and associated factors of blood donation among health care workers in Tikur Anbessa specialized Hospital. Addis Ababa, Ethiopia: Department of Emergency Medicine, College of Health Sciences, Addis Ababa University, 2015.

31 Malako D, Yoseph F, Bekele ML. Assessment of knowledge, attitude and practice and associated factors of blood donation among health care workers in Ethiopia: a cross-sectional study. BMC Hematol 2019;19:10

32 Mulatu K, Hailu T, Yegezu A, et al. Assesment of knowledge, attitude and practice on blood donation in AMAN sub City residents, South West, Ethiopia, 2015. Health Science Journal 2017;11:1.

33 Seid T, Dimtsu B, Zemene A. Voluntary blood donation practice and its associated factors among health care providers, at Axum town public health facilities Northern Ethiopia: a cross-sectional study. Curr Res complement Altern Med 2017:100007.

34 Tadesse T, Berhane T, Abraha TH, et al. Blood donation practice and associated factors among health professionals in Tigray regional state public hospitals, Northern Ethiopia. BMC Res Notes 2018;11:677.

35 Tadesse W, Ayalew Y, Yisma E. Knowledge, attitude, practice and associated factors towards voluntary blood donation among regular health science students of Samara University, Ethiopia. Health Sci J 2017;12:542.

36 Chopra D, Jauhari N. Knowledge attitude \& practices towards voluntary blood donation among medical students in Barabanki. Indian Journal of Community Health 2015;27:386-90.

37 Nwogoh B, Aigberadion U, Nwannadi Al. Knowledge, attitude, and practice of voluntary blood donation among healthcare workers at the University of Benin teaching Hospital, Benin City, Nigeria. J Blood Transfus 2013;2013:1-6. 